\title{
Cerebellar ataxia as the first manifestation of Alexander's disease
}

\author{
Ataxia cerebelar como manifestação inicial da doença de Alexander \\ Sheyla Ariêh de Souza Rezende', Maurício Fernandes', Renato Puppi Munhoz', Salmo Raskin², \\ Arthur Oscar Schelp³ ${ }^{3}$ Marjo S. van der Knaap 4 , Hélio A. G. Teive ${ }^{1}$

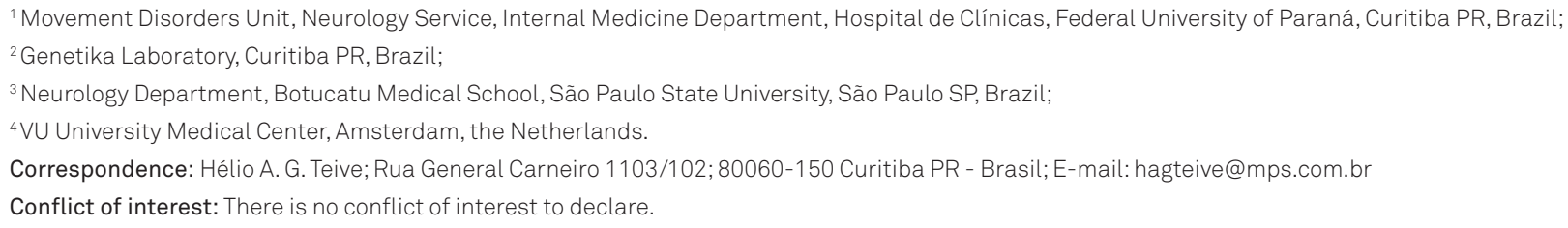

Alexander's disease $(\mathrm{AD})$ is a rare neurodegenerative disorder, classified as a leukodystrophy and characterized by macrocephaly, psychomotor regression, spasticity, ataxia, and seizures ${ }^{1}$. Neuropathologically, it is diagnosed by the presence of perivascular, periventricular, brainstem, and cerebellar eosinophylic intra-astrocytic cytoplasmic inclusions, which are called Rosenthal fibres ${ }^{1}$. AD is caused by mutations in the gene encoding glial fibrillary acidic protein (GFAP) on chromosome 17qq21, with an autosomal dominant inheritance ${ }^{1-3}$. The aim was to describe a female young patient with progressive cerebellar ataxia as the first manifestation of $\mathrm{AD}$.

A 13-year-old female was investigated because of a fouryear history of progressive gait disorder and incoordination. These progressive symptoms were accompanied by 


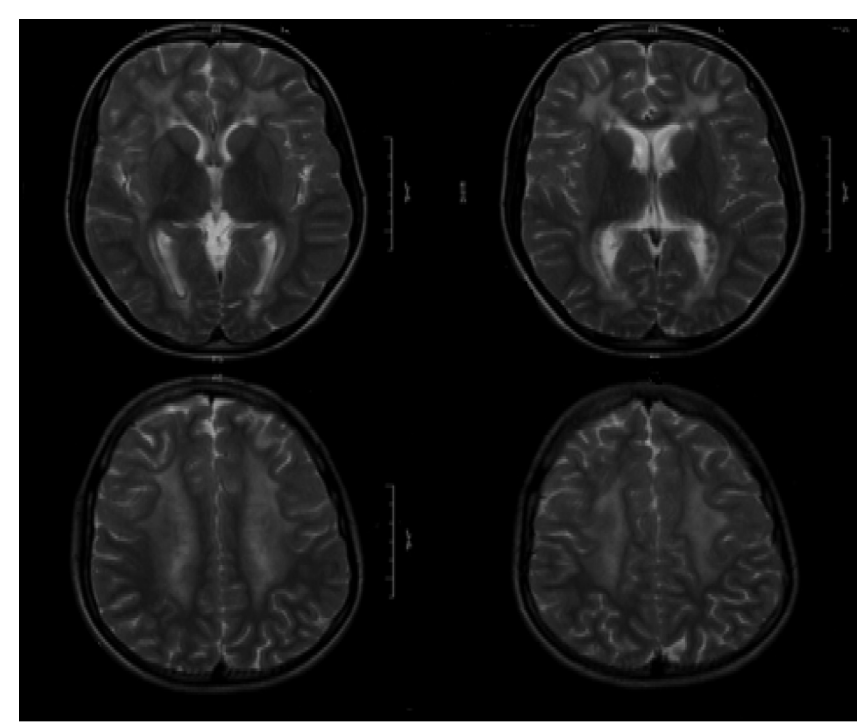

Figure. Brain magnetic resonance image of patient affected by Alexander's disease performed at age of 13. The images show bilateral and symmetrical hyperintensities on T2-wheighted in white matter, with frontal predominance suggestive of the diagnosis.

dysarthria, poor balance, and poor academic performance. Neurological examination showed mild cognitive impairment (MMSE=20), dysarthria, horizontal and vertical gazeevoked nystagmus, and gait ataxia. Brain magnetic resonance image (MRI) showed bilateral symmetric leukoencephalopathy, with frontal preponderance, without signal changes in the cerebellum (Figure). The patient was evaluated in another neurological service and she had an extensive work up, including anti-gliadin, anti-peroxidase, anti-thyroglobulin, and anti-GAD antibodies, spinal cord MRI, electroneuromyography, sural nerve biopsy, and tests for inherited metabolic disorders, including very long-chain fatty acid, arysulfatase A and beta-galactosidase activity test. These were all normal. Re-evaluation of brain MRI suggested the diagnosis of $\mathrm{AD}$. Molecular genetic test confirmed a heterozygous mutation (D157N) in the exons 2 and 8 (M4151) in the GFAP gene. The patien's mother was diagnosed with multiple sclerosis, treated with steroids and interferon. She had cerebellar ataxia and spasticity in the legs, and the brain MRI showed white matter abnormalities predominantly in both frontal lobes. She has a heterozygous mutation (M4151) in the exon 8 in the GFAP gene, confirming that she also had AD.

$\mathrm{AD}$ is divided into three different forms: typical infantile form, with onset before two years of age and rapidly lethal course; juvenile form, with onset between 2 and 12 years of age, with slower progression; adult-onset form, with onset after the age of 12 years, or during adulthood, with predominant involvement of the brainstem, with bulbar or pseudobulbar symptoms, such as dysarthria, dysphagia, pyramidal signs, palatal myoclonus, and cerebellar ataxia ${ }^{1}$.

MRI in early onset of $\mathrm{AD}$ is characterized by supratentorial periventricular white matter abnormalities, particularly in the frontal lobes. In adult-onset cases, MRI is often characterized by atrophy and signal abnormalities in the medulla oblongata and upper spinal cord ${ }^{1,3}$. Juvenile $\mathrm{AD}$ represents 17.8 to $24.2 \%$ of the total cases, and it is the least common form of the disease. It represents a continuum between the infantile form, with cortical and subcortical signs, and the adult one with cerebellar and brainstem signs ${ }^{1,4}$. Yoshida et al. ${ }^{4}$ proposed a new clinical guideline for diagnosis of $\mathrm{AD}$, including $\mathrm{AD}$ type 1 , or cerebral $\mathrm{AD}$, type 2 , or bulbospinal $\mathrm{AD}$, and type 3 or intermediate form of AD. This should be included in the differential diagnosis of cerebellar ataxia, with early and late onsets, in sporadic and hereditary cases ${ }^{1,5}$. Delnooz et al. ${ }^{5}$ described two sibs with $\mathrm{AD}$, hereditary late-onset ataxia, and only minimal white matter changes. The phenotypic spectrum of $\mathrm{AD}$ was enlarged after the definition of the molecular genetic diagnosis with GFAP analysis ${ }^{1-5}$.

\section{References}

1. Pareyson D, Fancellu R, Mariotti C, et al. Adult-onset Alexander disease: a series of eleven unrelated cases with review of the literature. Brain 2008;131:2321-2331.

2. Li R, Johnson AB, Salomons G, et al. Glial fibrillary acid protein mutation in infantile, juvenile, and adult forms of Alexander disease. Ann Neurol 2005;57:310-326.

3. van der Knaap MS, Naidu S, Breiter SN, et al. Alexander disease: diagnosis with MR imaging. Am J Neuroradiol 2001;22:541-552.
4. Yoshida T, Sasaki M, Yoshida M, et al. Nationwide survey of Alexander disease in Japan and proposed new guidelines for diagnosis. J Neuro 2011; May 1. [Epub ahead of print].

5. Delnooz CC, Schelhaas JH, van de Warrenburg BP, de Graaf RJ, Salomons GS. Alexander disease causing hereditary late-onset ataxia with only minimal white mater changes: a report of two sibs. Mov Disord 2008;23:1613-1615. 